\title{
Evaluating the material resource efficiency of secondary aluminium production: A Monte Carlo-based decision-support tool
}

\author{
Dimos Paraskevas $^{1 *}$, Giuseppe Ingarao ${ }^{2}$, Yelin Deng ${ }^{3}$, Joost R. Duflou ${ }^{4}$, Yiannis Pontikes ${ }^{1}$, \\ Bart Blanpain ${ }^{1}$ \\ ${ }^{1}$ Department of Materials Engineering, KU Leuven, Kasteelpark Arenberg 44, 3001, Heverlee, \\ Belgium \\ ${ }^{2}$ Department of Industrial and Digital Innovation (DIID), University of Palermo, Viale delle \\ Scienze, 90128, Palermo, Italy \\ ${ }^{3}$ Department of Civil and Environmental Engineering, Soochow University, Suzhou, 215131, \\ China \\ ${ }^{4}$ Department of Mechanical Engineering, KU Leuven, Celestijnenlaan 300A, 3001 Heverlee, \\ Belgium, Member of Flanders Make \\ * Corresponding Author: D. Paraskevas
}

\begin{abstract}
The contamination of aluminium streams during the different life cycle stages by alloy mixing and/or accumulation of foreign elements, in combination with the limited melt purification options during remelting, represents an important limiting factor in recycling. Consequently, in secondary aluminium production, primary aluminium is used to dilute the concentration of the residual elements, and alloying elements are added to adjust the composition to the target alloy specifications. However, adding elements, for which their refinement in a subsequent recycling step is problematic, results in permanent down-cycling or 'quality losses'. Hence, it is crucial to more efficiently control the composition of the metal streams prior to remelting. This article focuses on the aluminium cascade recycling chain and presents a Monte Carlo-based decisionsupport tool aiming to: i) identify all feasible clustering solutions per case based on input/output analysis; ii) quantify their environmental effect, and analyze the trade-offs; iii) consider scrap composition uncertainty/variability. Results reveal that primary resource additions can be minimized by optimizing metal sorting, and thus closing the recycling loop more effectively. Case studies are presented to illustrate the different functions of the tool, including examination of the Pareto front, and evaluation of the 'recyclability' of a scrap stream or a sorting solution into different alloy systems.
\end{abstract}

Keywords: Aluminium recycling; Life Cycle Assessment; material efficiency; alloying elements; scrap sorting.

Word count: 7.179 words 34 


\section{INTRODUCTION}

Recent research has revealed the importance of reducing the environmental impact caused by metals production and processing. Some authors provide overviews of the energy and resource efficiency of manufacturing processes (Ingarao, 2017; Duflou et al., 2012) and routes (Ingarao, 2018), others on sustainable metal recycling (Gutowski et al., 2013; Reuter et al., 2005, Paraskevas et al., 2016), metal recovery (Binnemans et al., 2015), and material efficiency (Allwood et al. 2011). Such studies aim to highlight the crucial importance of closing the technospheric mining loop more efficiently, as well as increasing the metal circularity at product level (Stotz et al., 2017)

Metal recycling also has environmental implications, however; depending on the degree of mixing and the level of accumulated impurity and alloying elements, substantial amounts of energy and resources may be required to recover, recycle and refine metals. Uncontrolled mixing and contamination of aluminium streams during the different life cycle phases, pose a great challenge during the final recycling step of remelting as refining options are limited for the case of aluminium. As a result, dilution and quality losses occur during open loop recycling (Amini et al, 2007; Nakajima et al. 2010; Nakamura et al., 2012; Paraskevas et al., 2015). The thermodynamic barriers in metal refining are explained in section 1.1.

\subsection{Metallurgical limitations in subsequent metal uses}

In pyro-metallurgical processes, melt separation and purification are governed by the laws of thermodynamics. Recent studies, based on thermodynamic simulations, indicate which elements can be removed during recycling of various base metals. More specifically, the recycling of aluminium (Nakajima et al., 2010), steel (Nakajima et al., 2011), copper (Nakajima et al., 2011), titanium (Lu et al. 2012), and magnesium (Hiraki et al., 2011) alloys have been examined. Thermodynamics dictates that it is impossible to remove some elements from the melt. For 
aluminium remelting the refining options are much more limited compared to other base metals, such as steel and copper. Among the 45 alloying and impurity elements that usually occur in aluminium, only six elements can be removed to some extent. The only major alloying elements that can be refined are $\mathrm{Mg}$ in the slag phase by oxidation and $\mathrm{Zn}$ in the gas phase by evaporation (Nakajima et al., 2010). Figure 1 presents the Ellingham diagram of the standard free energies $\left(\Delta \mathrm{G}^{0}\right)$ for the formation of the oxides of aluminium and its major alloying elements as a function of temperature (T), as further confirmation of this argument. As can be seen, Mg oxidation has lower $\Delta \mathrm{G}^{0}$ than the aluminium oxidation reaction at a wide range of temperatures. This indicates that $\mathrm{Mg}$ can be oxidized prior to aluminium, and therefore has the potential to be removed by oxidation mechanisms in the slag phase. The rest of the elements (Fe, Cu, $\mathrm{Zn}, \mathrm{Si}, \mathrm{Mn}$ ) have higher $\Delta \mathrm{G}^{0}$ than $\mathrm{Al}$ oxide reaction, indicating the opposite. As consequence of the above metallurgical limitations, the secondary aluminium production operates in a cascade recycling chain. The resulting environmental challenges of open look recycling are presented in section 1.2.

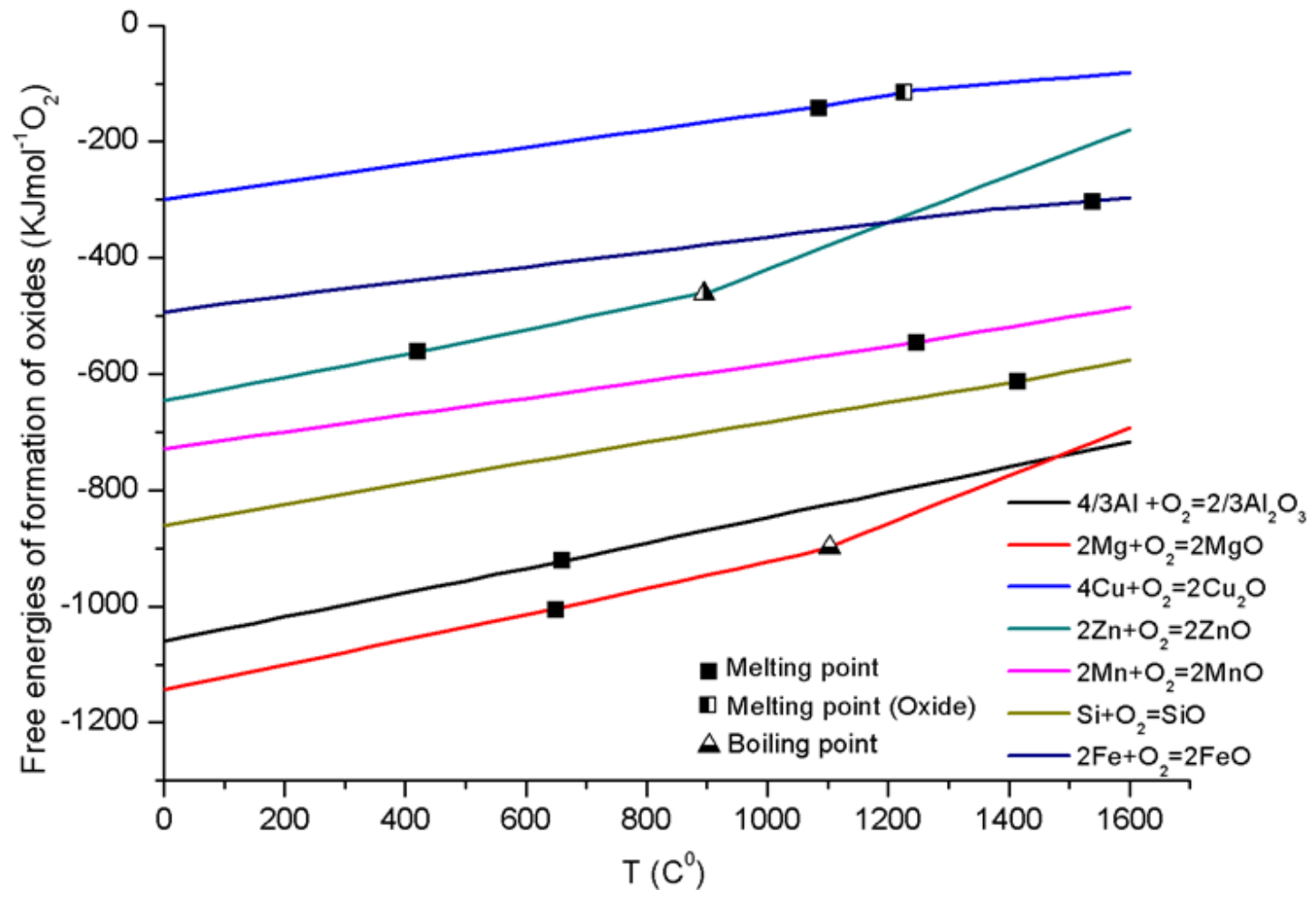

Figure 1: The Ellingham diagram with a change of $\Delta \mathrm{G}^{0}$ for the formation of oxides as a function of temperature (T), for partial oxygen pressure of 1atm (calculated with FactSage v7.1 software). 


\subsection{The metal sorting problem and resulting environmental challenges}

Mixed scrap is recycled into a higher entropy alloy system as accumulation of alloying and/or impurity elements occurs (transition from wrought to cast alloys). Associated with this open loop or cascade recycling are dilution and quality losses (Amini et al., 2007; Nakajima et al., 2011).

Quality losses (in terms of entropy increase) occur when the metal input composition no longer matches the original alloys due to alloy mixing and contamination. The addition of alloying elements during remelting results in further quality losses. Dilution losses (in terms of environmental impact increase) occur when primary metal is added in order to meet the composition requirements of a target alloy, thus 'diluting' the concentration of the residual elements. Both dilution and quality losses lead to further primary material consumption, scrap underutilization, and, thus, a decrease in the overall material efficiency of the system. Today, dilution and cascade recycling can effectively provide a solution and absorb all scrap, mainly due to the increased aluminium demand, which cannot be met by recycling only. The question remains whether it is a sustainable solution in the longer term.

Annually, nearly 6.1 Mt of wrought aluminium scrap is down-cycled into cast products, and 8.0 Mt per year of primary aluminium is used for dilution (Cullen and Allwood, 2013). Cast alloys act as a sink in the aluminium cascade recycling chain by absorbing downgraded mixed alloy streams. Cast alloys practically can only be recycled into cast alloys. However; these serve a limited number of applications, and are mostly only used in vehicles engines (Nakajima et al. 2010). Modaresi (2014) and Hatayma et al. (2012) both indicate that the continuous down-cycling (accumulation of alloying element), along with vehicle development (e.g. introduction of electrical vehicles), will result in a significant unrecyclable (due to the high alloy content) scrap surplus in the coming decades and suggest enhanced scrap sorting to mitigate these effects.

In recent years, the economic and environmental benefits of optimized scrap sorting have been the focus of a number of researchers. Nakamura et al. (2012) and Ohno et al. (2017) focused on the 
dilution and quality losses associated with the recycling of ferrous metals from End-of-Life Vehicles (ELV), and provide sorting strategies to reduce these losses. The accumulation of $\mathrm{Cu}$ has been identified as the limiting factor. Lovik et al. (2014), by using a dynamic substance flow analysis of aluminium and its alloying elements from automotive, outline various interventions in metal management and recycling paths to maximize scrap utilization. Soo et al. (2018), focusing also on ELV, characterised the types of joining techniques causing impurities in the aluminium streams, and identified the linkage among particle size reduction and the presence of impurities. Based on the impurity levels due to joints, they quantified dilution and quality losses.

Other researchers focussed on demonstrating the extent and effect of functionality loss in steel life cycles, highlighting the related repercussions in terms of environmental impact and the benefits of conserving the functionality of major alloying elements used in steel production (Diener and Tillman, 2015; Reijnders, 2016) . Nakamura et al. 2017 highlighted the importance of sorting by developing an alloy-based model (MaTrace-alloy) to track the fate of metals embodied in each product over multiple life cycles of products. The results revealed that when applying a high level of scrap sorting, greater than $70 \%$ of the initial functionality of $\mathrm{Cr}$ and $\mathrm{Ni}$ could be retained over a period of 100 years, whereas under a poor level of sorting, it could plunge to less than $30 \%$.

Ohno et al. (2014) underlined the importance of proper sorting as one of the most promising strategies in order to avoid loss of functionality and to optimise scrap waste absorption into new steel production. They analysed the ELV-generated scrap streams, documenting the benefits if they are sorted according to their alloying content. Closed-loop recycling can mitigate this effect of cascade recycling. For aerospace alloys closed alloy loops can offer significant environmental and economic benefits over downcycling (Eckelman et al., 2014).

Life Cycle Assessment (LCA), as defined in ISO 14040 (ISO, 2006), is a systematic method to quantify environmental impacts related to products and/or processes within a pre-defined system boundary and functional unit. Based on an LCA analysis, Niero and Olsen (2016) present the 
benefits of optimized scrap batch selection for the case of aluminium beverage cans. Taking into account input-output compositions, they identify $\mathrm{Mn}$ as the limiting alloying element for can-tocan recycling. Paraskevas et al., (2015) used goal programming as a multi-objective optimization method to maximize scrap usage and minimize the addition of alloying elements during secondary aluminium production. Gaustad et al. (2011), by combining dynamic material flow analysis with blending models, quantified both environmental and cost savings obtainable with proper scrap allocation methods. Chang et al. (2015) applied a cluster analysis strategy to increase aluminium dross utilization. Li et al. (2011) examined the use of optimization models to identify economically efficient sorting strategies and their impact on scrap usage. Based on this methodology they evaluated the benefits of cast and wrought alloy separation. Changes to the alloy tolerances, reverse logistics and new sustainable business models prove to be the key elements for a more efficient utilisation of post-consumer scrap into wrought alloy aluminium (Martinsen and Gulbrandsen-Dahl, 2015).

All the above research highlights the importance of compositionally closing the metal recycling loops to minimise dilution losses and/or loss of functionality in order to maximise material efficiency. Alloying elements can be either impurities or useful elements during recycling, depending on how the scrap streams are pre-sorted or clustered. Thus, the alloying elements resource efficiency is of great importance in metal recycling. However, this is often neglected in conventional LCA-based studies for simplification reasons.

\subsection{Contributions of the developed model}

The present research focuses to answers two main research questions, 'How should aluminium streams be sorted or clustered prior to recycling to maximise the material resource efficiency?

Which are the environmental trade-offs of the various feasible sorting solutions?'. Both questions are not properly addressed yet, as either the metal sorting/clustering problem is approached as a 
single objective (cost) optimisation problem without capturing the environmental trade-offs, or the scrap composition and compositional uncertainty are not considered. However, from an environmental perspective, metal clustering is a multi-objective problem with conflicting objectives: i) minimum primary aluminium addition; ii) minimum alloying element addition. Thus, it is important to examine the Pareto front to identify the environmental trade-offs between feasible solutions.

Monte Carlo simulation is a method to take into account the impact of uncertainty in forecasting models by calculating the predicted outcome using stochastically distributed input variables. The developed tool combines Monte Carlo analysis to search the solution space for metal clustering varying the mass and compositions of the available material inputs, and using LCA to quantify the related environmental impact for each solution. It takes into account the composition and compositional uncertainty of the input materials, and decomposes the sorting problem to clear objectives: minimum primary aluminium addition and minimum alloying elements addition. The tool enables the identification of all feasible sorting solutions to meet the target alloy specifications, while recording all values of interest. In this way the proposed decision support tool enables the: i) calculation of the scrap absorption and primary metal inputs for each solution, ii) quantification of the direct environmental impacts of each solution; iii) identification of the Pareto frontier and analysis of the environmental trade-offs. At the production level, this method can serve as a tool that can aid remelters and refiners in adapting their optimal metal management strategies by altering the material inputs to maximize material efficiency per case. Section 2 provides a detailed scope and method description for the proposed Monte Carlo-based decision support tool.

\section{MATERIALS AND METHODS}

\subsection{Selection of alloying elements scope}


As shown by Nakajima et al. (2010), during aluminium remelting, the only elements that can be refined from the major alloying elements ( $\mathrm{Cu}, \mathrm{Fe}, \mathrm{Si}, \mathrm{Mg}, \mathrm{Zn}$, and $\mathrm{Mn})$, are $\mathrm{Mg}$ and $\mathrm{Zn} . \mathrm{Mg}$ can be removed in the slag phase by oxidation, and $\mathrm{Zn}$ in the gas phase by evaporation (Figure 1). In fact, $\mathrm{Mg}$ can be refined from the melt by melt purification treatments widely used in the industry, such as fluxing (Mashhadi et al., 2009) or flotation/de-gassing (Reuter et al., 2005). Zn has a boiling temperature of around $900^{\circ} \mathrm{C}$ (Figure 1). Above this temperature, $\mathrm{Zn}$ has the potential to be removed in the gas phase and recovered by distillation technologies (Ohtoki et al., 2000). Therefore $\mathrm{Mg}$ and $\mathrm{Zn}$ were excluded from the analysis described in this paper, as they do not pose a significant challenge in aluminium purification. Other refining technologies, such as fractional crystallization, are reported as more energy intensive than primary aluminium production (Gaustad et al. 2012). Hence, the analysis focuses on the four alloying elements of aluminium alloys $(\mathrm{Fe}, \mathrm{Si}, \mathrm{Cu}$, and $\mathrm{Mn})$ that cannot be refined from the melt.

\subsection{Model description}

The environmental impact values of the primary resources, used as input for the Monte Carlo model, are presented in Table 1. The environmental impact is expressed at the endpoint level considering the following areas of impact: Human Health (HH); Ecosystem Diversity (ED); and Resource Depletion (RD). These three endpoint levels of damage are weighted through an averaging scheme specified in the ReCiPe Endpoint H/A method (Goedkoop et al.,2006), and converted into a single point indicator expressed in Ecopoints $(\mathrm{Pt})$. The environmental single point score $(\mathrm{Pt})$ is used to benchmark several scenarios with respect to their environmental burden.

Table 1: Impact assessment values for the primary material additions, according to Paraskevas et al. (2015)

\begin{tabular}{cccccc} 
Impact & $\begin{array}{c}\text { Damage to } \\
\text { HH } \\
(\text { DALY*E- } \\
4 / \text { tonne })\end{array}$ & $\begin{array}{c}\text { Damage to ED } \\
\text { (species.yr*E-6 } \\
\text { /tonne })\end{array}$ & $\begin{array}{c}\text { Damage to } \\
\text { RA/ton } \\
(\$ / \text { tonne })\end{array}$ & $\begin{array}{c}\text { Overall } \\
\text { impact } \\
(\text { Pt/tonne })\end{array}$ & Comments \\
\hline
\end{tabular}




\begin{tabular}{cccccc}
$\begin{array}{c}\text { Primary } \\
\text { Aluminium }\left(\mathrm{I}_{\mathrm{Al}}\right)\end{array}$ & 245.5 & 89.9 & 47278 & 1001.0 & $\begin{array}{c}\text { Primary Al } \\
\text { production }\end{array}$ \\
Pig Iron $\left(\mathrm{I}_{\mathrm{Fe}}\right)$ & 41.1 & 13.1 & 8505 & 167.0 & $\begin{array}{c}\text { Fe as alloying } \\
\text { element }\end{array}$ \\
$\begin{array}{c}\text { Silicon }\left(\mathrm{I}_{\mathrm{Si}}\right) \\
\mathrm{Cu}, \begin{array}{c}\text { regional storage } \\
\left(\mathrm{I}_{\mathrm{Cu}}\right)\end{array}\end{array}$ & 98.1 & 58.1 & 26231 & 499.0 & $\begin{array}{c}\text { Si metallurgical } \\
\text { grade) as alloying } \\
\text { element }\end{array}$ \\
$\begin{array}{c}\text { Mn, regional } \\
\text { storage }\left(\mathrm{I}_{\mathrm{Mn}}\right)\end{array}$ & 100.7 & 24.4 & 24672 & 417.0 & $\begin{array}{c}\text { M as alloying } \\
\text { element } \\
\text { element }\end{array}$ \\
\hline
\end{tabular}

Figure 2 presents the proposed methodology and Table 2 presents the input variables and the recorded outputs. First, the Monte Carlo analysis was performed in all case studies using Model Risk Industrial version 5.3.8.9. Each Monte Carlo simulation, per case, was performed for 100,000 trials (samples or sets of input values) and a set of output values was recorded per trial. Table 3 lists the input variables of the model, the selected distributions, as well as the recorded outputs of the Monte Carlo runs.

As shown in Figure 2, the methodology used has four discrete levels: First, the definition of the input variables (masses of the input primary aluminium, alloying elements, and scrap batches) and their distributions, as discussed in the next section; Second, the Monte Carlo simulations, in which all sets of solutions are recorded (see Table 2) and filtered based on the desired alloy tolerance limits for the alloying elements, taking into account the composition uncertainty of the scrap batches; Third, based on the feasible set of solutions, i.e. those that comply with the desired alloy compositional specifications (ASM International, 1998), dilution and quality losses are calculated by Equations 7 and 8 respectively; and Fourth, the filtered solutions are plotted in the Dilution versus Quality Losses (DQL) Diagrams (Figure 2d).

Assuming no metal losses during remelting, to produce one tonne of the desired aluminium alloy,

the summation of all primary (primary aluminium and alloying elements) and secondary materials (scrap batches) should be equal to $1000 \mathrm{~kg}$. This mass constraint is expressed mathematically by Equation (1), for $n$ scrap batches and $e$ alloying element batches (Fe, $\mathrm{Cu}, \mathrm{Si}, \mathrm{Mn}$ ). 


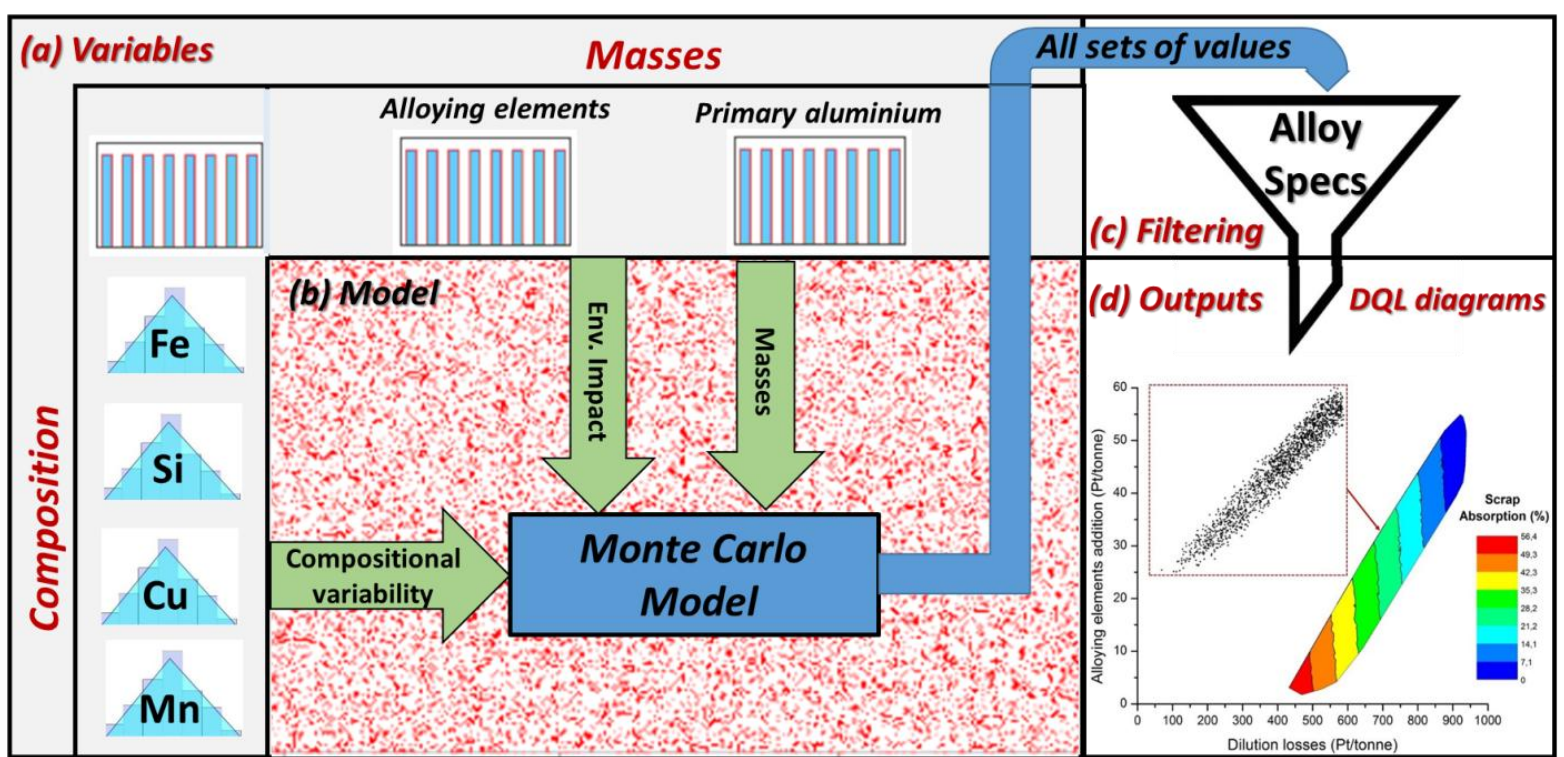

Figure 2: Outline of the decision support tool with the: (a) input variables, which are the material batches in step uniform distributions, as well as the composition of the scrap batches in continuous triangle distributions; (b) Monte Carlo model; (c) filtering of all Monte Carlo trials into feasible solutions based on the target alloy specification (Equation 7); (d) mapping of Dilution and Quality Losses (DQL) of the feasible solutions.

Table 2: Input variables of the Monte Carlo model as well as output/recorded values.

\begin{tabular}{|c|c|c|c|c|}
\hline Input Variables & Index & Unit & $\begin{array}{c}\text { Type of } \\
\text { distributions }\end{array}$ & Variation \\
\hline $\begin{array}{l}\text { Concentration of problematic } \\
\text { alloying elements e (e=Fe, } \mathrm{Si} \text {, } \\
\mathrm{Cu}, \mathrm{Mn}) \text { in the scrap batches }\end{array}$ & $\mathrm{C}_{\text {sc_e }}$ & $\mathrm{wt} \%$ & $\begin{array}{l}\text { Triangle } \\
\text { continuous }\end{array}$ & $\pm \mathrm{u} \%$ from $\bar{x}$ eq. (5) \\
\hline $\begin{array}{l}\text { Mass of Alloying elements } \\
\text { addition (e=Fe, } \mathrm{Si}, \mathrm{Cu}, \mathrm{Mn})\end{array}$ & $\mathrm{M}_{\mathrm{e}}$ & $\mathrm{kg}$ & $\begin{array}{l}\text { Discrete step } \\
\text { uniform }\end{array}$ & $\begin{array}{l}\text { Min: } 0 \text { kg / Max: eq. (2) } \\
\text { Step: } 0.1 \mathrm{~kg}\end{array}$ \\
\hline Mass of available scrap batches & $\mathrm{M}_{\mathrm{sc}}$ & $\mathrm{kg}$ & $\begin{array}{l}\text { Discrete step } \\
\text { uniform }\end{array}$ & $\begin{array}{l}\text { Min: } 0 \text { kg / Max: eq. (3-4) } \\
\text { Step: } 0.1 \mathrm{~kg}\end{array}$ \\
\hline Mass of primary aluminium (Al) & $\mathrm{M}_{\mathrm{Al}}$ & $\mathrm{kg}$ & $\begin{array}{l}\text { Discrete step } \\
\text { uniform }\end{array}$ & $\begin{array}{c}\text { Min: } 0 \text { kg / Max: eq. (1) } \\
\text { Step: } 0.1 \mathrm{~kg}\end{array}$ \\
\hline Outp & Index & Unit & & Comments \\
\hline Masses of all material inputs & $\begin{array}{c}\mathrm{M}_{\mathrm{sc}}, \mathrm{M}_{\mathrm{Al}} \\
\mathrm{M}_{\mathrm{e}} \\
\end{array}$ & $\mathrm{kg}$ & \multicolumn{2}{|c|}{$\begin{array}{l}\text { Index: sc for scrap batches; } \mathrm{Al} \text { for primary } \\
\text { aluminium; e for alloying elements }\end{array}$} \\
\hline $\begin{array}{l}\text { Concentration of alloying } \\
\text { elements in the produced alloy }\end{array}$ & $\mathrm{C}_{\text {alloy_e }}$ & $\mathrm{wt} \%$ & \multicolumn{2}{|c|}{ Calculated by Equation 6} \\
\hline Dilutio & D & $\mathrm{Pt}$ & \multicolumn{2}{|c|}{$\begin{array}{l}\text { Impact caused by the addition of primary } \\
\text { aluminium. Calculated by Equation } 8\end{array}$} \\
\hline Quality losses & Q & $\mathrm{Pt}$ & \multicolumn{2}{|c|}{$\begin{array}{c}\text { Impact caused by the addition of alloying } \\
\text { element. Calculated by Equation } 9\end{array}$} \\
\hline Scrap absorption & - & $\mathrm{wt} \%$ & \multicolumn{2}{|c|}{ Calculated by Equation 10} \\
\hline
\end{tabular}




\subsubsection{Variables distribution types and boundaries}

The developed Monte Carlo model runs varying masses of primary (primary aluminium and alloying elements) and secondary (different scrap batches) material inputs, according to the mass constraint as shown in Equation 1. To scan the solution space more efficiently, a discrete step uniform distribution (Figure 1) for the material masses was selected. This choice excludes quasi identical solutions by imposing a $0.1 \mathrm{~kg}$ accuracy step (a smaller step size is also allowed). Since the functional unit is $1000 \mathrm{~kg}$ of produced alloy, the selected step size provides a good accuracy. Moreover, when compared to the continuous uniform distribution, the same number of runs/sample gives better exploration of the solution space as quasi identical solutions are not examined. The uniform distribution assures that all mass will have the same probability to be selected within the chosen boundary. The model runs values (stepwise) of alloying elements (e) from $0 \mathrm{~kg}$ to the maximum allowed concentration of each specific element of the desired aluminium alloy output (Equation 2). For example, if the maximum concentration of $\mathrm{Si}$ in the desired alloy is $9.5 \% \mathrm{wt}$, the model varies the mass values for $\mathrm{Si}$ accumulation from 0 to $95 \mathrm{~kg}$. The boundaries of input values in the Monte Carlo model within the selected distributions are presented below:

$$
M_{e}=\text { Value within the discrete (step) uniform distribution from } 0 \text { to } 1000 * C_{\text {max_e }}
$$

where $\mathrm{C}_{\text {max } \_ \text {e }}$ is the maximum tolerance limit (ASM International, 1998) of element e in the target alloy (expressed as a fraction: $\mathrm{kg} / \mathrm{kg}$ ). Then, for the scrap batches (sc) the maximum boundaries for $n$ scrap batches are defined by Equations 3 and 4, which represent the remaining mass from our functional unit, excluding the alloying element content:

$$
\begin{gathered}
M_{s c_{1}}=\text { Value within the uniform distribution from } 0 \text { to }\left(1000-\sum_{e=1}^{4} M_{e}\right) \text { (3) } \\
M_{S c_{I}}=\text { Value within the uniform distribution from } 0 \text { to }\left(1000-\sum_{e=1}^{4} M_{e}-\sum_{I=1}^{I-1} M_{S c}\right)
\end{gathered}
$$


where $\mathrm{I}$ is the number of the scrap batch $(\mathrm{n} \geq \mathrm{I}>1)$. The mass for primary aluminium (Al) is then calculated from Equation 1.

A critical issue in recycling and waste management is the compositional uncertainty of the secondary resources (aluminium mixed scrap in this case). To take into account the effect of compositional uncertainty in the scrap batches, the alloying elements' concentrations have been considered as additional variables in the Monte Carlo model. Such uncertainty has been included in the model by considering continuous triangle distribution with $\mathrm{u} \%$ variation $(\mathrm{u}=10 \%$ variation in this study) from the mean $\bar{x}$ compositional value of each scrap stream. Alternatively, compositional measurements of scrap streams should be collected, plotted and curve fitted to define a distribution per considered case. As also similar data are missing from the literature, it has been considered that the triangle distribution is a good first approximation for modelling scrap compositional uncertainty. Equation 5 describes alloying elements (e) concentration variables for the scrap batches (sc):

$\mathrm{C}_{\mathrm{sc}_{-} \mathrm{e}}=$ Value within the continuous triangle distribution from $0.9 \bar{x}$ to $1.1 \bar{x}(5)$

Then the concentration of alloying elements in the produced alloy can be calculated by:

$$
C_{\text {alloy_e }}=\frac{\left(\sum_{s c} M_{S c} C_{S C_{\_} e}+\sum_{e} M_{e} C_{e}+M_{A l} C_{A l_{-} e}\right)}{1000}
$$

\subsubsection{Filtering Monte Carlo results to solution and output recorded values}

The filtering of the Monte Carlo results is performed based on the desired/target alloy specifications (minimum and maximum tolerance limits, $\mathrm{C}_{\mathrm{e}_{-} \min }$ and $\mathrm{C}_{\mathrm{e} \_ \text {max }}$, respectively) as defined by Equation 7 for each element (four filtering steps). The solutions that do not comply with the compositional constraints of the target/desired alloy are excluded from further analysis.

$$
C_{\text {emin }} \leq C_{\text {alloy_e }} \leq C_{e \max }(7)
$$

The ASM Handbook (1998) provides more than 450 aluminium alloy designations/compositions.

The calculated alloying element concentrations for each run of input variables are further used to filter all the Monte Carlo solutions into feasible solutions. Varying the masses of the material 
inputs and taking into account the compositional uncertainty of the scrap batches, multiple feasible solutions can be found and evaluated based on material efficiency indicators such as dilution and quality losses. Dilution losses caused by the addition of primary aluminium to reduce the concentration of the alloying elements in the input scrap batches, and quality losses caused by the addition of alloying elements that will circulate permanently in the metal cycle (as they cannot be refined) are also recorded for each set of solutions. They are calculated by Equations 8 and 9, respectively:

$$
\begin{aligned}
& D=M_{A l} I_{A l}(8) \\
& Q=\sum_{e} M_{e} I_{e}(9)
\end{aligned}
$$

where $\mathrm{I}_{\mathrm{Al}}$ and $\mathrm{I}_{\mathrm{e}}$ represent the overall environmental impact expressed in Ecopoints Pts/1000kg of primary aluminium production and alloying elements (e.g. $\mathrm{I}_{\mathrm{Fe}}$ for Pig Iron) respectively. Equation 10 is used to calculate the wt\% scrap absorption of each feasible solution.

$$
\text { Scrap absorption }=\sum_{s c} \frac{M_{s c}}{1000} * 100(10)
$$

Single point solutions are theoretically feasible and indicate a single sorting solution for the production of a given alloy given the material input constraints (availability and composition). It is also possible that a global minimum is found, meaning a sorting solution which assures minimum dilution (primary aluminium) and quality losses (alloying elements additions). On the other hand, no solution would mean that all possible combinations of the available material inputs do not meet the target alloy compositional tolerance limits or the mass balance constraint is not fulfilled.

\section{RESULTS AND DISCUSSION}

\subsection{Case study selection}

Based on the above described model, several scenarios have been analyzed to illustrate the potential of the decision support tool. The case studies can be grouped into two categories: i) the 
production of wrought aluminium alloys, where dilution losses are dominant; and ii) the production of cast alloys where quality losses (caused by the addition of alloying elements) have a significant environmental impact contribution. For wrought alloys, the production of AA6061 (a commonly used 6xxx alloy, especially in extrusion, with a large number of applications) has been selected. For cast alloys, the production of 380.0 and 355.0 alloys, as typical cast alloys, has been examined. This choice was driven by the need to investigate the 'recyclability' of common Endof-Life scrap streams (SC1-SC3 in Table 3) in the selected target wrought and cast alloys. The chemical composition of the examined scrap streams, the primary Al used as dilution agent, and the target alloys' composition tolerance limits are reported in Table 3. Compositional uncertainty of $\mathrm{u}=10 \%$ from the mean values was considered for all scrap batches (in continuous triangle distribution).

Table 3: Chemical composition (mean values) of the examined scrap streams SC1-SC3, of primary $\mathrm{Al}$ used as dilution agent, and the tolerance limits of the target alloys.

\begin{tabular}{|c|c|c|c|c|c|c|}
\hline Index & Description & $\begin{array}{l}\text { Fe } \\
(w t \\
\%)\end{array}$ & $\begin{array}{c}\mathrm{Si} \\
(\text { wt \%) }\end{array}$ & $\begin{array}{c}\mathrm{Cu} \\
(\mathrm{wt} \%)\end{array}$ & $\begin{array}{l}\text { Mn } \\
(w t \\
\%)\end{array}$ & Source \\
\hline SC1 & $\begin{array}{l}\text { Al Engines and } \\
\text { transmissions }\end{array}$ & 0.68 & 8.61 & 2.69 & 0.27 & Kirchain and Cosquer (2007) \\
\hline SC2 & $\begin{array}{l}\text { Vehicles } \\
\text { (wrought } \\
\text { products) }\end{array}$ & 0.45 & 1.79 & 0.26 & 0.16 & Hatayama et al., 2012 \\
\hline SC3 & $\begin{array}{c}\text { Used Beverage } \\
\text { Can scrap (UBC) }\end{array}$ & 0.50 & 0.30 & 0.22 & 1.10 & Stotz et al., 2017 \\
\hline Al & Primary Al & $0-0.2$ & $0-0.1$ & 0 & 0 & $\begin{array}{l}\text { London Metal Exchange, } \\
\qquad 2010\end{array}$ \\
\hline & AA6061 & $0-0.7$ & $0.4-0.8$ & $0.15-0.40$ & 0.15 & ASM International, 1998 \\
\hline 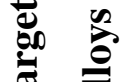 & 355.0 & $0-0.6$ & $4.5-5.5$ & $1.0-1.5$ & 0.50 & ASM International, 1998 \\
\hline & 380.0 & $0-2.0$ & $7.5-9.5$ & $3.0-4.0$ & 0.50 & ASM International, 1998 \\
\hline
\end{tabular}




\subsection{Dilution versus Quality Losses 2D/3D diagrams - Pareto frontier and trade-offs}

Based on the filtered solutions of the Monte Carlo model, by varying material input masses and considering the scrap compositional uncertainty, the solutions that satisfy the target alloy specification are used to calculate dilution (D) and quality losses (Q) (Equations 8-9). Each sorting of solutions has a different wt\% scrap content (Equation 10). These feasible sorting solutions can be depicted in 2D 'Dilution-Quality Losses' (DQL) scatter diagrams (e.g. Figure 3), or in 3D DQL diagrams, which include the wt\% scrap absorption of each solution as a third dimension (e.g. Figure 4). In these graphs, the $x$ axis shows the impact of primary aluminium addition, and the $y$ axis the impact of the addition of alloying elements.

Figure 3a presents the DQL diagram of the sorting solutions for the production of AA6061, 355.0, and 380.0 alloys by utilizing SC3 (Used Beverage Cans or UBC scrap), primary aluminium, and alloying elements. UBC scrap is a relatively pure scrap stream as it is composed of two wrought alloys. A first observation is that the higher the compositional tolerance limits of the target alloy (here, 380.0 is the highest, AA6061 the lowest), the lower the dilution losses can be, as a higher proportion of scrap can be absorbed. By contrast, with higher tolerance limits, the addition of alloying elements can result in higher environmental costs, as more alloying elements may be required to meet the desired alloy specifications. As an alternative, more downgraded scrap can substitute the addition of virgin alloying elements. The tool enables evaluation of the 'recyclability' of a scrap stream for the production of different alloys.

Figure $3 \mathrm{~b}$ presents the sorting solution for the production of the AA6061 by UBC scrap. The red line depicts the Pareto front. The scrap 'sorting' problem is clearly a multi-objective optimization problem. Most of the times we cannot minimize the addition of both primary aluminium and alloying elements simultaneously; such objectives are conflicting. Consequently, an appropriate optimization strategy can be found using the Pareto front analysis. Solutions that require lower levels of addition of the alloying elements, by substituting these elements with the scrap alloy 
content, are in the lower values of the $y$-axis expressing dilution losses. Solutions that require lower primary aluminium addition are in the lower values of the $x$-axis, expressing quality losses, within the solution space. In general, quality losses represent a much lower environmental impact than dilution losses (one order of magnitude lower as can be seen from Figure 3a); however, as discussed, these elements cannot be refined afterwards and will circulate in the aluminium cycle. For this reason, the direct impact of the addition of alloying elements should not be the only indicator, and second-order effects on the sustainability of the aluminium cycle have to be considered in future studies.
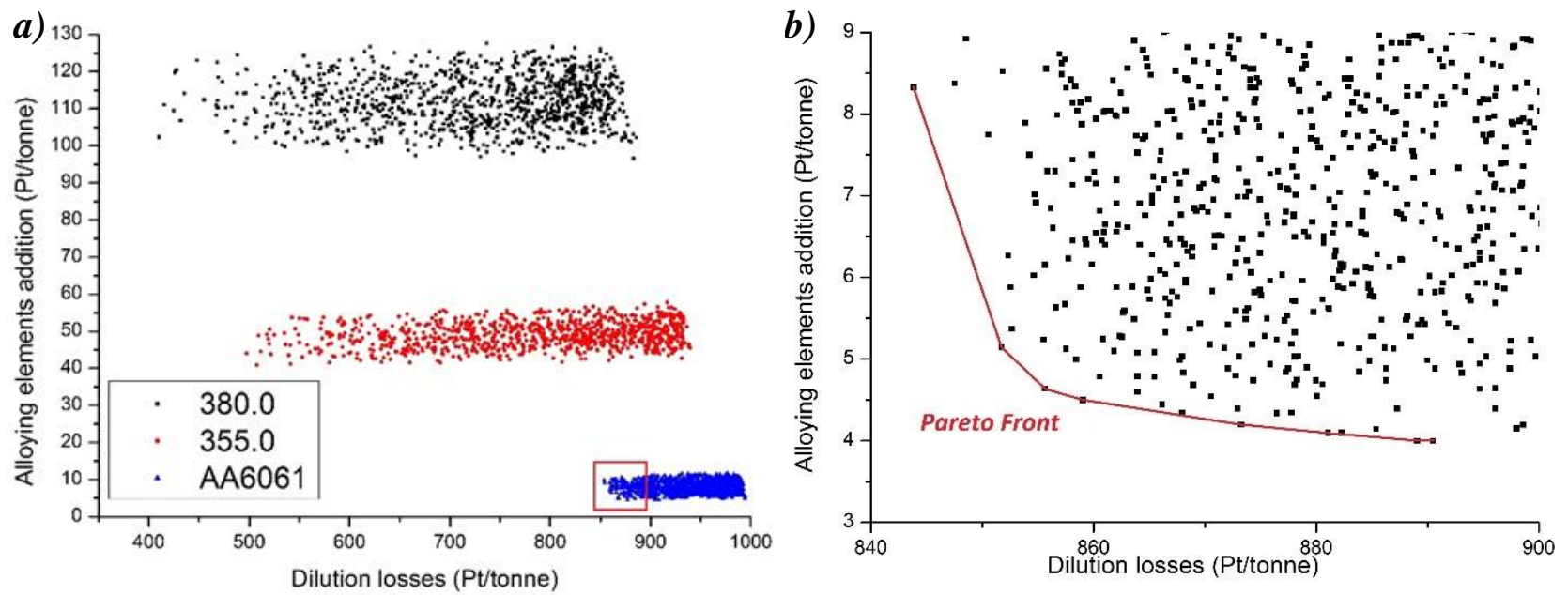

Figure 3: (a) 2D-DQL diagram with the feasible solution of the model of utilizing SC3 (UBC scrap), primary Al, and alloying elements for production of AA6061, 355.0, and 380.0 alloys; (b) Magnification of the maximum scrap absorption solutions (indicated by red box in Figure 3a) for the production of AA6061. The Pareto front is depicted by a red line.

The higher the achieved scrap absorption, the lower the primary material resource additions are.

The maximum scrap absorption percentages of SC3 (UBC scrap) for the production of 380.0, 355.0, and AA6061 alloys are identified as 47.15\%, 44.7\%, and 13.7\%, respectively. However, the wt\% scrap absorption of the sorting solutions is not depicted in the 2D DQL diagrams, such as in Figure 3. To add this information, the proposed tool can generate 3D DQL diagrams where the solution space of the sorting solution can be enriched with the wt $\%$ scrap absorption levels. Similarly, Figure 4 represents an example of utilizing SC1 (scrap from Al engines and 
transmissions; see Table 3), primary aluminium, and alloying elements for the production of the 380.0 cast alloy. The solution space with the maximum \% scrap absorption sorting is highlighted in the red zone.

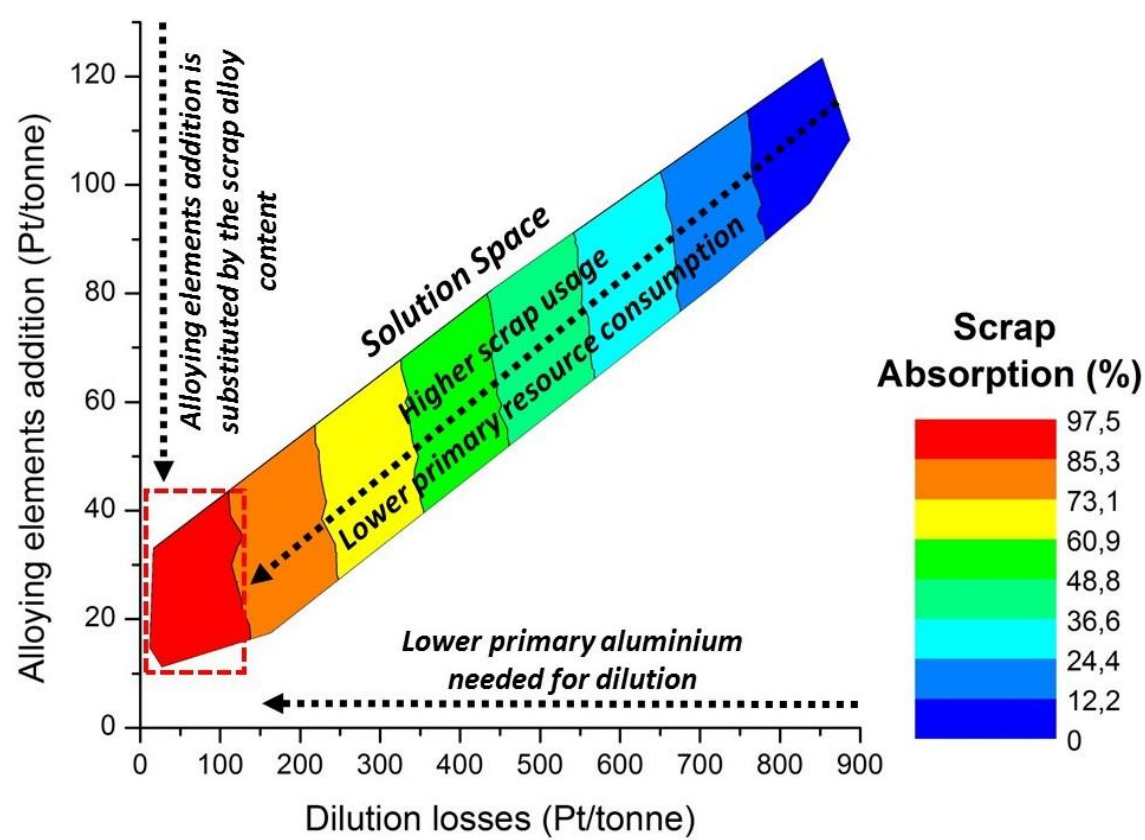

Figure 4: (a) DQL diagram with multiple solutions (as solution space) for producing the cast 380.0 alloy utilizing SC1 (scrap from Al engines and transmissions), primary aluminium, and alloying elements. The red box indicates the \% maximum scrap usage solution area.

\subsection{Recyclability of scrap streams in wrought alloys: The case of AA6061 production.}

Wrought alloys have strict and low tolerance limits for alloying elements. In consequence, they do not easily absorb mixed alloy scrap streams, and their production is heavily dependent on primary aluminium consumption. Figure 5 presents the case of producing AA6061 using the material batches given in Table 3. Figure 5a depicts the various mixing solutions of the scrap stream SC1 (scrap from engines and transmissions of vehicles) with virgin aluminium and alloying elements. Similarly, Figures $5 \mathrm{~b}$ and $\mathrm{c}$ represent the solutions for utilizing SC2 (scrap from the wrought aluminium products of vehicles) and SC3 (scrap from used beverage cans, UBC), respectively. SC2 has a higher scrap usage potential for the production of AA6061 (up to 43.4\%), than SC3 (up to $14.9 \%)$ and SC1 (8.8\%), because SC2 has a composition more similar to AA6061. In general, primary aluminium addition is reduced by utilizing purer scrap streams instead. Quality losses are 
relatively low as the compositional tolerance limits of AA6061 are narrow at low concentrations. Figure $5 \mathrm{~d}$ depicts the scatter solutions of Figures 5a-c together with the additional solutions obtained by mixing these scrap streams. By effectively mixing SC1-3 scrap batches, higher levels of scrap absorption can be achieved (up to $48.5 \%$ ), which reduces the associated dilution and quality losses. Generally, for wrought alloy production, dilution losses are dominant and investigation is required to identify compositionally more similar (e.g. from the same wrought alloy family) or purer scrap streams that could replace primary aluminium addition.

a)
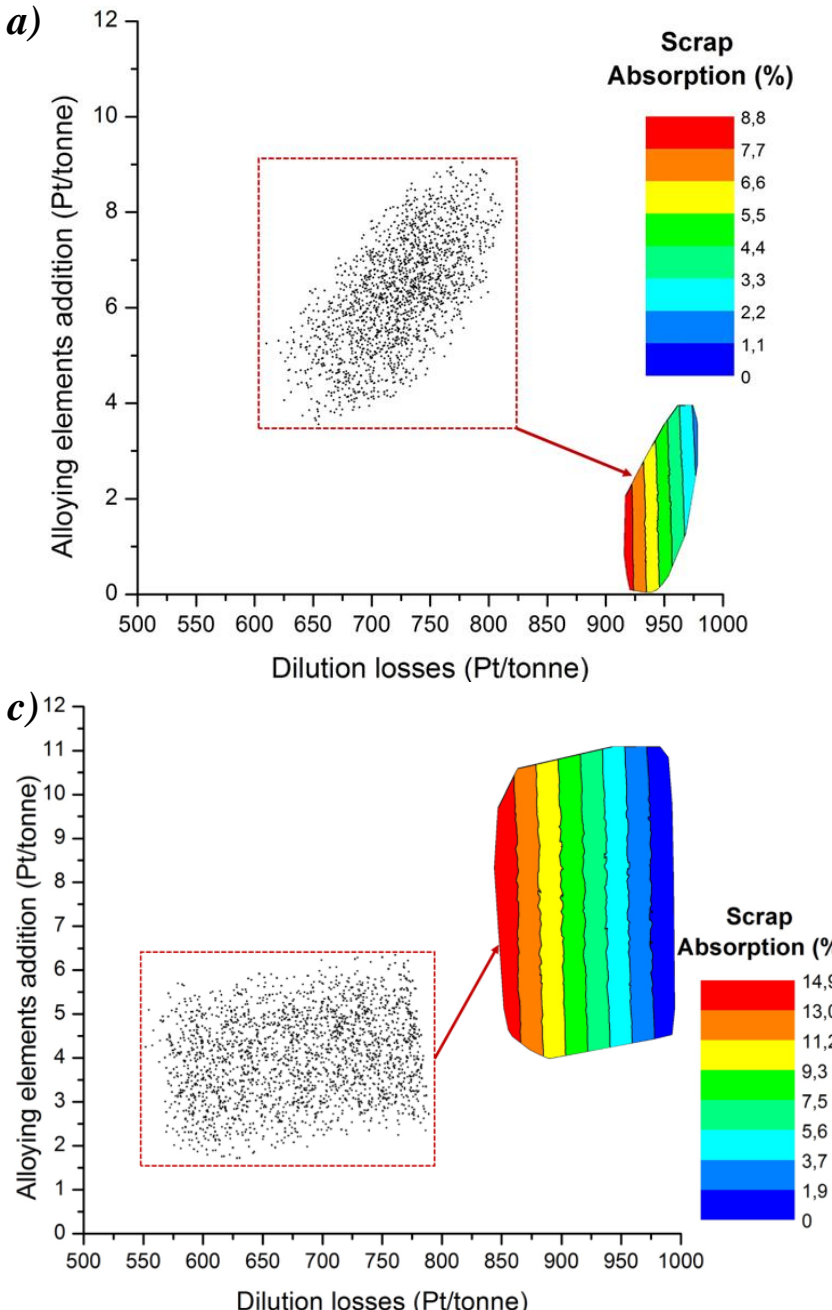
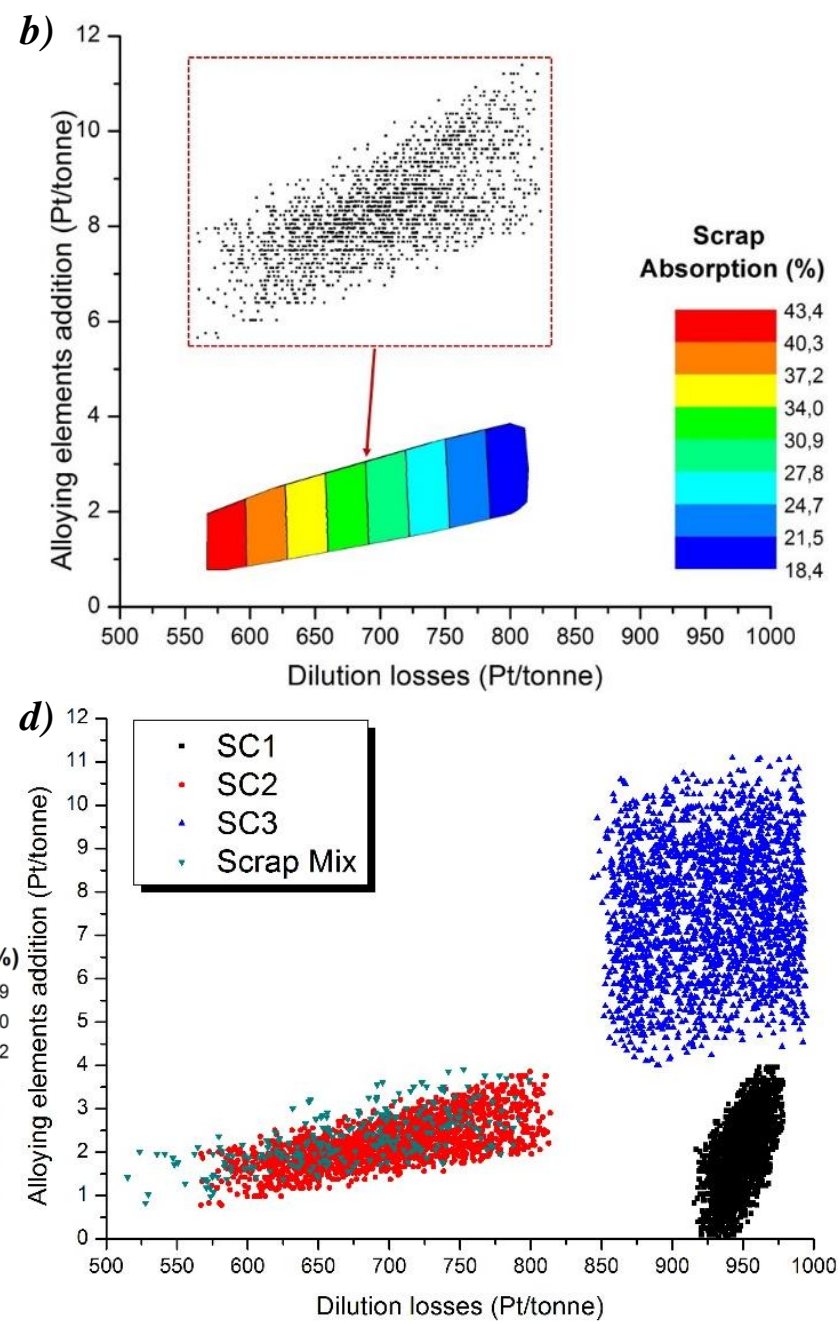

Figure 5: (a-c) 3D DQL diagram with multiple solutions (as solution space, and magnified in scatter diagrams) for producing the wrought AA6061 utilizing SC1-3 (scrap from: Al engines and transmissions; wrought products from vehicles; and UBC respectively), primary $\mathrm{Al}$, and alloying elements; and (d) 2D DQL diagrams with all solutions as scatter diagrams. The additional solutions of scrap mixing are depicted in green. 


\subsection{Recyclability of scrap streams in cast alloys: The case of 355.0 production.}

Downgraded or mixed alloy scrap streams are mainly diverted to cast alloys where the tolerance limits are higher. Cast alloys thus act as a sink in the aluminium cascade recycling chain, but their applications are quite limited, mainly in automotive components. Figure 6 presents the case of the production of the common 355.0 alloy utilizing the material batches given in Table 3. Figure 6a depicts the various mixing solutions of scrap stream SC1 with primary aluminium and alloying elements. Figures $6 \mathrm{~b}$ and c represent the solutions for utilizing SC2 and SC3, respectively. Figure $6 \mathrm{~d}$ depicts the scatter solutions of Figures $6 \mathrm{a}-\mathrm{c}$, together with the additional solutions obtained by mixing these scrap streams.

Once again, SC2 has a higher scrap usage potential for the production of 355.0 cast alloy (up to 96.5\%); SC1 and SC3 solutions are characterized by a scrap usage potential of $56.4 \%$ and $44.8 \%$, respectively. The direct impact of alloying element addition is much higher than in the case of wrought alloys. Thus, it is crucial for cast alloy production to focus on increasing the resource efficiency of the alloying elements and minimize their addition in the aluminium cycle. By utilizing highly alloyed scrap streams, the alloying element addition can be substituted with scrap alloy content. Using purer scrap streams (SC1 and SC2), dilution losses can be reduced; however, higher levels of alloying element addition may be required. By mixing of scrap streams (as seen in Figure 6d) there is a solution that offers a small increase of scrap absorption (99.8\%wt), compared to the already good recyclability of SC2 (96.5\%wt). Scrap mixing significantly reduces the direct impact of alloying element addition, however, the main environmental benefits come from minimizing the additions of alloying elements. Rather than downgrading 'purer' wrought scrap stream by the addition of alloying elements, these streams are mixed with the cast scrap stream. Figure $6 \mathrm{~d}$ represents the extra sorting solution, with much lower quality losses, that can be found by mixing SC1-3. 

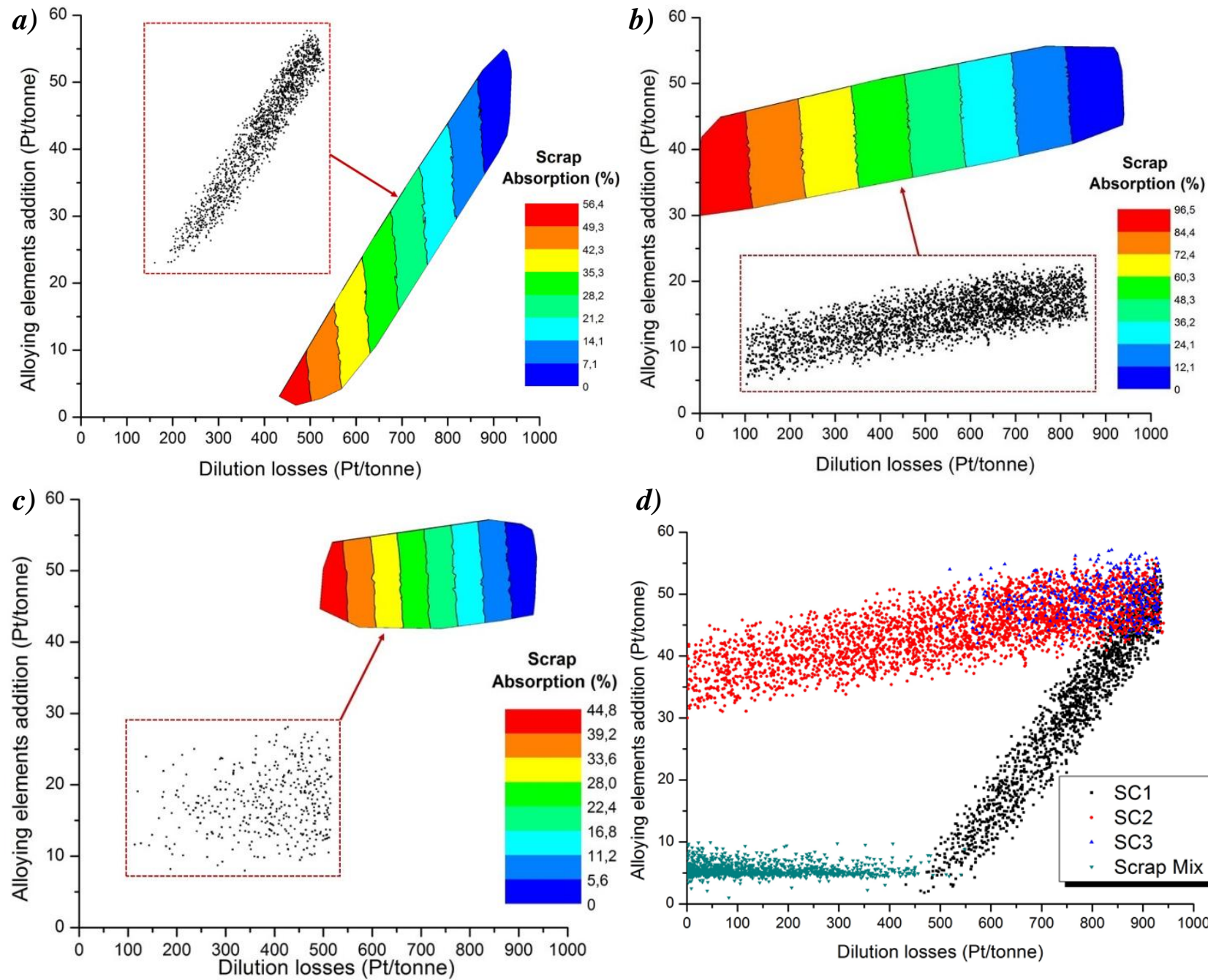

d)

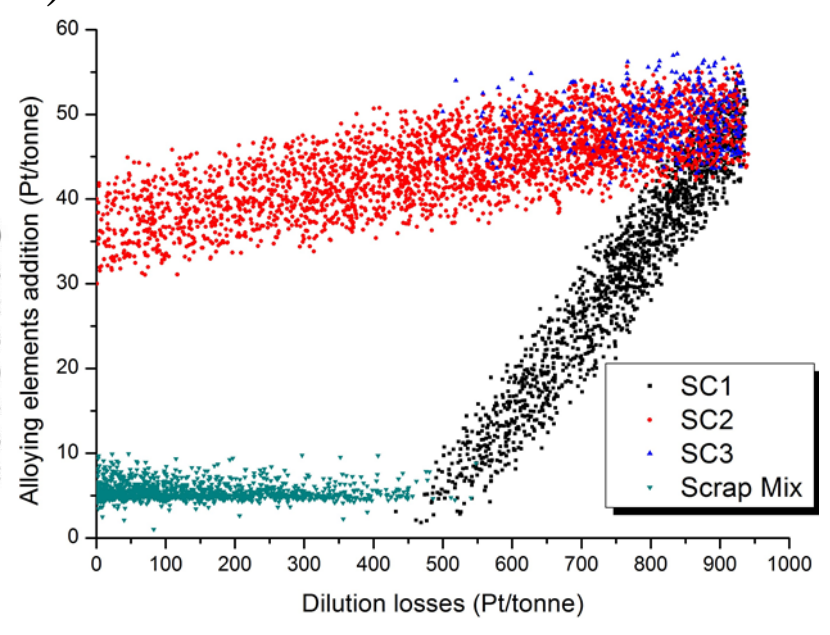

Figure 6: (a-c) 3D DQL diagrams diagram with multiple solutions (as solution space and magnified in the scatter diagrams) for producing the cast 355.0 alloy utilizing SC1-3 (scrap from $\mathrm{Al}$ engines and transmissions; wrought products from vehicles; and UBC respectively), primary Al, and alloying elements; (d) 2D DQL diagrams with scatter diagrams of all solutions. The additional solutions of scrap mixing are depicted in green.

\subsection{Outlook}

The contamination of the aluminium streams in combination with the limited melt refining options can result in: i) primary resource depletion; ii) scrap under-utilization; and iii) down-cycling. Currently, the scrap availability cannot meet demand and, thus, all aluminium scrap has the potential to be recycled. The resource efficiency of the alloying elements is often neglected, however. Through inefficient scrap sorting, alloying elements can become contaminants instead of useful elements. It is crucial for the sustainability of the aluminium recycling chain, therefore, to 
move from open to compositionally 'tighter' recycling loops in order to maximize the overall material resource efficiency of the system. As shown by Liu et al. (2013), the aluminium in-use stocks and flows set major boundary conditions for future emission pathways of the aluminium sector, with significant implications for climate change mitigation strategies.

Within this context, the proposed Monte Carlo-based decision-support tool aims to:

- Map all possible metal sorting solutions per case (with one or multiple scrap batches, alloying elements and primary alumnium as considered material inputs)

- Quantify the direct environmental impacts of different possible solutions related to their primary resource consumption

- Examine the environmental trade-off solutions of each sorting solution.

- Evaluate the 'recyclability' of single or mixed scrap streams, considering the scrap compositional uncertainty, for the production of different alloys (see 2D and 3D DQL diagrams). In this way a metal sorting scenario can be defined on a case by case basis.

- Identify sustainable sorting clustering solutions or strategies that maximize material utilization and, thus, minimize quality and dilution losses.

The presented decision-support tool that can be easily adopted and adapted by aluminium remelters/refiners to define their optimal metal management strategy, in order to maximize scrap utilization and minimize primary metal additions. At a macro-economic level, combined with a Material or Substance Flow Analysis (MFA/SFA), the tool can be used for environmental policy analysis. Primary aluminium addition can be minimized by better utilizing purer scrap streams. The addition of alloying elements, responsible for permanent quality losses, can be minimized by identifying a scrap stream or a scrap mixture which is compositionally closer to the target alloy, with the suitable alloy content. An optimal metal sorting strategy for aluminium flows will eventually result in less problematic alloying elements being inserted into the aluminium cycle. 


\section{References}

Allwood, J.M., Ashby, M.F., Gutowski, T.G., Worrell, E., 2011. Material efficiency: A white paper. Resour. Conserv. Recycl. 55 (3), 362-381.

Amini, S.H., Remmerswaal, J., Castro, M.B., Reuter, M.A. 2007. Quantifying the quality loss and resource efficiency of recycling by means of exergy analysis, J. Cleaner Prod. 15, 907-913.

ASM International, 1998. Chemical compositions and international designations for aluminum alloys. Metals Handbook Desk Edition, second ed. , pp 426-436.

Binnemans, K, Jones, P.T., Blanpain, B., Van Gerven, T.V., Pontikes, Y., 2015. Towards zerowaste valorisation of rare-earth-containing industrial process residues: a critical review. J. Cleaner Prod., 99, 17-38.

Chang, J., Olivetti, E., Fjeldbo, S. K., Kirchain. R., 2015. Data Mining Toward Increased Use of Aluminum Dross. J. Sustain. Metall., 1, 53-64.

Cullen, J.M., Allwood, J.M., 2013. Mapping the Global Flow of Aluminum: From Liquid Aluminum to End-Use Goods. Environ. Sci. Technol. 47(7), 3057-3064.

Diener, D.L., Tillman A.M., 2015. Component end-of-life management: Exploring opportunities and related benefits of remanufacturing and functional recycling. Resour. Conserv. Recycl. 102, 80-93.

Duflou, J.R., Sutherland, J., Dornfeld, D., Herrmann, C., Jeswiet, J., Kara, S., Hauschild, M., Kellens, K., 2012. Towards energy and resource efficient manufacturing: a processes and systems approach. CIRP Ann. 61 (2), 587-609.

Eckelman, M.J., Ciacci, L., Kavlak, G., Nuss, P., Reck, B.K., Graedel, T.E., 2014. Life cycle carbon benefits of aerospace alloy recycling. J. Cleaner Prod. 80, 38-45.

Gaustad, G., Olivetti, E., Kirchain, R., 2011. Toward Sustainable Material Usage: Evaluating the Importance of Market Motivated Agency in Modeling Material Flows. Environ. Sci. Technol. $45,4110-4117$.

Gaustad, G., Olivetti, E., Kirchain, R., 2012. Improving aluminium recycling: A survey of sorting and impurity removal technologies. Resour. Conserv. Recycl. 58, 79-87.

Goedkoop, M., Heijungs, R., Huijbregts, M., De Schryver, A.M., Struijs, J., van Zelm, R., 2009. ReCiPe 2008, first ed. In: A Life Cycle Impact Assessment Method Which Comprises Harmonised Category Indicators at the Midpoint and the Endpoint Level. Report I: Characterisation

Gutowski, T., Allwood, J.M., Sahni, S., Hermann, C.A., 2013. Global assessment of manufacturing: Economic development, energy use, carbon emissions, and the potential for energy efficiency and materials recycling. Annu. Rev. Environ. Resour. 38, 81-106.

Hatayama, H., Daigo, I., Matsuno, Y., Adachi, Y., 2012. Evolution of aluminum recycling initiated by the introduction of next-generation vehicles and scrap sorting technology. Resour. Conserv. Recycl. 66, 8-14.

Hiraki, T., Takeda, O., Nakajima, K., Matsubae, K., Nakamura, S., Nagasaka, T., 2011. Thermodynamic criteria for the removal of impurities from end-of-life magnesium alloys by evaporation and flux treatment. Sci. Technol. Adv. Mater. 12, 035003. 
Ingarao, G, Priarone, P.C., Deng, Y., Paraskevas, D., 2018. Environmental modelling of aluminium based components manufacturing routes: Additive manufacturing versus machining versus forming. J. Cleaner Prod. 176, 261-275.

Ingarao, G., 2017. Manufacturing strategies for efficiency in energy and resources use: The role of metal shaping processes. J. Cleaner Prod. 142, 20, 2872-2886.

ISO, 2006. ISO 14040 Environmental Managementdlife Cycle Assessmentdprinciples and Framework. International standard. International Organisation of Standardisation, Geneva.

Kirchain, R., Cosquer, A., 2007. Strategies for maintaining metal reuse: insights from modeling of firm-wide raw materials availability and demand. Resour. Conserv. Recycl., 51, 367-396.

Li, P., Dahmus, J., Guldberg, S., Riddervold, H. O., Kirchain, R., 2011. How Much Sorting Is Enough? Identifying Economic and Scrap-Reuse Benefits of Sorting Technologies. J. Ind. Ecol., 743-759.

Liu, G., Bangs, E.C., Müller, D.B. 2013. Stock dynamics and emission pathways of the global aluminium cycle. Nat. Clim. Change, 3, 338-342.

London Metal Exchange, 2010. Special Contract Rules for High Grade Primary Aluminium. www.aseemglobal.com/pdf/LME_Specifications_for_Primary_Aluminium_111010.pdf, Last accessed 09/04/2018.

Løvik, A.N., Modaresi, R., Müller, D.B., 2014. Long-Term Strategies for Increased Recycling of Automotive Aluminum and Its Alloying Elements. Environ. Sci. Technol. 48, 4257-4265.

Lu, X., Hiraki, T., Nakajima, K., Takeda, O., Matsuabe, K., Zhu, H.-M., Nakamura, S., Nagasaka, T., 2012. Thermodynamic analysis of separation of alloying elements in recycling of end-oflife titanium products. Sep. Purif. Technol. 89, 135-141.

Martinsen, K., Gulbrandsen-Dahl, S., 2015. Use of Post-consumer Scrap in Aluminium Wrought Alloy Structural Components for the Transportation Sector. Procedia CIRP, 29, 686-691.

Mashhadi, H.A., Moloodi, A., Golestanipour, M., Karimi, E.Z.V., 2009. Recycling of aluminium alloy turning scrap via cold pressing and melting with salt flux. J. Mater. Process. Technol., 209 (7), 3138-3142.

Modaresi, R., Løvik, A.N., Müller, D.B., 2014. Component- and Alloy-Specific Modeling for Evaluating Aluminum Recycling Strategies for Vehicles. JOM, 66: 2262

Nakajima, K., Takeda, O., Miki, T., Matsubae, K., Nagasata, T., 2011. Thermodynamic analysis for the controllability of elements in the recycling process of metals. Environ. Sci. Technol. 45, 4929-4936.

Nakajima, K., Takeda, O., Miki, T., Matsubae, K., Nakamura, S., Nagasaka, T., 2010. Thermodynamic analysis of contamination by alloying elements in aluminium recycling. Environ. Sci. Technol. 44, 5594-5600.

Nakamura, S., Kondo, Y., Matsubae, K., Nakajima K., Tasaki, T., Nagasaka, T., 2012. Qualityand Dilution Losses in the Recycling of Ferrous Materials from End-of-Life Passenger Cars: Input-Output Analysis under Explicit Consideration of Scrap Quality. Environ. Sci. Technol., 46, 9266-9273. 
Nakamura, S., Kondo, Y., Nakajima, K., Ohno, H., Pauliuk, S., 2017 Quantifying Recycling and Losses of $\mathrm{Cr}$ and $\mathrm{Ni}$ in Steel Throughout Multiple Life Cycles Using MaTrace-Alloy. Environ. Sci. Technol. 51, 9469-9476.

Niero, M., Olsen, S. I., 2016. Circular economy: To be or not to be in a closed product loop? A Life Cycle Assessment of aluminium cans with inclusion of alloying elements, Resour., Conserv. Recycl. 114, 18-31

Ohno, H., Matsubae, K., Nakajima, K., Kondo, Y., Nakamura, S., Fukushima, Y., Nagasaka, T., 2017. Optimal Recycling of Steel Scrap and Alloying Elements: Input- Output based Linear Programming Method with Its Application to End-of-Life Vehicles in Japan. Environ Sci Technol., 51(22), 13086-13094.

Ohno, H., Matsubae, K., Nakajima, K., Nakamura, S., Nagasaka, T., 2014. Unintentional Flow of Alloying Elements in Steel during Recycling of End -of-Life Vehicles. J. Ind. Ecol. 18, 2242253.

Ohtaki, M., Arakawa, T., Murata, F., 2000. A new proposal of continuous agitation vacuum distillation process (CAVP) to remove $\mathrm{Zn}$ from aluminum scrap melt. In Proceeding of the Fourth International Symposium on Recycling of Metals and Engineered Materials. TMS: The Minerals, Metals, and Materials Society, Pittsburgh, Pennsylvania, October 22-25, 2000

Paraskevas, D., Dadbakhsh, S., Vleugels, J., Vanmeensel, K., Dewulf, W., Duflou, J.R., 2016. Solid state recycling of pure $\mathrm{Mg}$ and $\mathrm{AZ31} \mathrm{Mg}$ machining chips via spark plasma sintering. Mater. Des. 109, 520-529.

Paraskevas, D., Kellens, K., Dewulf, W., Duflou, J.R., 2015. Environmental modelling of aluminium recycling: a Life Cycle Assessment tool for sustainable metal management. J. Cleaner Prod. 105, 357-370.

Reijnders, L., 2016. Conserving functionality of relatively rare metals associated with steel life cycles: a review. J. Cleaner Prod. 131, 76-96.

Reuter, M.A., Boin, U.M.J., van Schaik, A., Verhoef, E., Heiskanen, K., Yang, Y., Georgalli, G., 2005. The Metrics of Material and Metal Ecology: Harmonizing the Resource, Technology and Environmental Cycles. Elsevier Science: Amsterdam.

Soo, V.K., Peeters, J., Paraskevas, D., Compston, P., Doolan, M., Duflou, J.R., 2018.Sustainable aluminium recycling of end-of-life products: A joining techniques perspective. J. Cleaner Prod. 178, 119-132.

Stotz, P.M, Niero, M., Bey, N., Paraskevas, D., 2017. Environmental screening of novel technologies to increase material circularity: A case study on aluminium cans. Resour., Conserv. Recycl. 127, 96-106. 